\title{
Endovascular (non-operative) abdominal aortic aneurysm treatment: Where are we?
}

\author{
Ali Gürbüz ${ }^{1}$
}

1) İzmir Ataturk Training and Research Hospital Cardiovascular Surgery Clinic, Prof. MD, Izmir / Turkey

\begin{abstract}
Though the long-term mortality and morbidity results of patients who underwent endovascular treatment modalities are unknown, we recommend endovascular treatment to be administered in patients with high risk for open surgery and in centers with proper hybrid o-perating room conditions. In view of the tendency for less invasive methods for the treatment option in recent years, cardiovascular surgeons should review their positions on this. Assu-ming the 52\% of the vascular interventions in 2012 will be performed via endovascular routes, the importance of this will be understood again. Cardiovascular surgery specialists are at a crossroads.
\end{abstract}

Keywords: Aortic aneurysm, aneurysm diameter, endovascular treatment 
Aortic aneurysm is a condition in which the normal diameter in a localized site expands more than $50 \%$ ( 1.5 fold). Normal infrarenal aorta diameter is $21.4 \mathrm{~mm}$ in males and $18.7 \mathrm{~mm}$ in females. Abdominal aortic aneurysm (AAA) can be explained as the diameter of infrarenal aorta at a localized site permanently exceeding $3 \mathrm{~cm}$. It is seen $5 \%$ of males over 50 years. This rate increases with the increasing average age and advancements in diagnostic modalities. ${ }^{(1)}$ AAA generally shows $0.5 \mathrm{~cm}$ expansion per year, and rupture develops as a result of its natural progress. Until rupture stage, mostly, asymptomatic course is observed. The risk of rupture is proportional to the diameter, and is increased in aneurysms over $5.5 \mathrm{~cm}$. The cases should be treated under elective condition before rupture development. ${ }^{(1,2,3)}$

\section{Clinical Presentation}

Approximately $75 \%$ of the cases have asymptomatic course. Symptoms are usually manifested with the growth of aneurysm sack, and rupture, embolization and thrombosis as a result of the pressure of this growth to surrounding tissues. ${ }^{(2)}$

\section{Clinical symptoms can be examined in three groups:}

1- Asymptomatic period: Includes approximately $75 \%$ of AAAs, and is detected by routine examination or testing.

2- Symptomatic period: The most common symptom is abdominal and low-back pain. Abdominal pain may be continuous or intermittent, mild or severe. As a result of the pressure of aneurysm sack, nausea, vomiting, dyspepsia may occur. It may manifest itself with extremity ischemia due to distal embolization or aneurysm thrombosis.

3- Rupture Period: Severe abdominal and low back pain that has sudden onset and do not change with position indicates rapid growth or rupture. Approximately $20 \%$ of the cases in our country admits to hospital with rupture. Rupture patients are in shock, cold, sweaty and hypotensive. ${ }^{(2,4)}$

\section{Diagnosis}

Detection of aneurysms over $3.5 \mathrm{~cm}$ with physical examination is actually $15 \% .5$ Currently, ultrasonography (USG) remains to be valueble for the initial diagnosis. Also, Contrast-enhanced Computerized Tomography $(\mathrm{CT})$ which is a successful, relatively cheap, fast, and a reliable diagnostic modality in showing the rupture and aneurysm extension is a good option especially in patients who will undergo surgery. Contrast-enhanced CT should include thoracoabdominal sections. This way, accompanying thoracic aneurysms can also be detected. Angiography should be preferred generally in cases with accompanying peripheral arterial disease, renal artery stenosis or fistulization suspicion.

While mortality (30-day) in elective surgery cases is approximately $5 \%$, it is around $50 \%$ in rupture patients. As this rate only includes the patients who reach the hospital, the real mortality rate of ruptured abdominal aneurysms is around $90 \%$. Due to high mortality of the rupture, early diagnosis and elective treatment show the importance USG screening especially in patients over 60-65 years with AAA-related risk factors.

\section{AAA related risk factors:}

- Smoking

- Family history

- Hypertension

- COPD (Chronic obstructive pulmonary disease)

- Atherosclerotic disease (carotid stenosis, peripheral artery disease, etc.)

- Peripheral artery aneurysm (especially popliteal and iliac artery)

\section{Treatment}

Aneurysm diameter has a great importance in the treatment of AAAs. The risk of rupture development under $5 \mathrm{~cm}$ is reported to be $5 \% .{ }^{(6)}$ Annual risk of rupture that is increased proportionally with aneurysm diameter has been stated to be $0 \%$ for $<4 \mathrm{~cm}, 1 \%$ for 4.5 $\mathrm{cm}, 11 \%$ for $5.5 \mathrm{~cm}$ and $26 \%$ for $6.5 \mathrm{~cm}$. As is seen, there is a logarithmic relation between diameter increase and the risk of rupture. Many surgeons believe 
that surgery should be preferred in conditions in which the risk of rupture is more than the operative risk. One group advocates early surgical intervention (under 5 $\mathrm{cm}$ ) and states that operative mortality is very low in young cases with low risk of surgery, that comorbidity and surgical risk may increase with the advancing age, and that for these reasons early surgical intervention is a good option.

In AAA with the diameter of $3-5 \mathrm{~cm}$, in patients with no or less than $0.5 \mathrm{~cm}$ annual aneurysm diameter increase, follow-up is recommended.

- Patients whom recommended operative treatment (Surgery indications)

- Patients with an active live and AAA diameter of $5.5-5.9 \mathrm{~cm}$

- All patients with the diameter of $6 \mathrm{~cm}$ and over

- Symptomatic patients with rapid diameter increase ( $>0.5 \mathrm{~cm}$ in 6 months)

- There are two strategies as surgical treatment methods.

- Open surgery

- Endovascular surgery (EVAR)

- While 30-day mortality of open surgery technique in elective AAA repair in 5\%, and it has

$15-30 \%$ rate of major complications. ${ }^{(7)}$ Operative mortality may reach upto $50 \%$ in high risk patients. ${ }^{(8)}$ Foreseeable major risks during classic surgical intervention are perioperative cardiac injury, and respiratory and renal failure.

At the present day, in addition to AAA screening, another factor that may reduce mortality rate and is a new treatment modality is endovascular aneurysm repair (EVAR) which is becoming widespread with fields of indication increasing day by day.

EVAR is applied since 1990s. In our country and our clinic, it became available in 2000s. It is a minimal invasive method as the physiological stress in the body and mortality rate is 3 -fold less than open surgery, it is associated less morbidity and shorter anesthesia and intensive care period. 9 The efficacy of this method is still being investigated in clinical trials, and the trials in which the early- and medium-term results can be assessed were conducted (UK-EVAR, DREAM, EUROSTAR). Long-term results remain to be unknown. $(10,11,12,13,14,15)$

Eligibility for EVAR Treatment: In order for AAA cases to be eligible for endovascular procedure, they need to have vascular anatomic properties. Contrastenhance multislice CT and angiographic imaging are used for this. According to this:

- Aneurysm neck length should be $>15 \mathrm{~mm}$

- Diameter of the neck should be $<30 \mathrm{~mm}$

- Neck angle should be $>60^{\circ}$

- Mural thrombus in the neck should be $<2 \mathrm{~mm}$

- The diameter of external iliac artery should be $>7 \mathrm{~mm}$

- Iliac angle should be $>90^{\circ}$

- Terminal aorta (Common iliac artery bifurcation) should be $>20 \mathrm{~mm}$.

Grafts used in EVAR Treatment: As the initial grafts had aorto-aortoic tubular structure, there was a high rate of early complications. At the present day usually, branched (aorto-biiliac) or straight aortoiliac (aorto-uniiliac) grafts with stent are used. When uniiliac grafts are used, the contralateral iliac artery is occluded, thereby femoro-femoral bypass is performed. With the development of fenestrated stent grafts, stent extension at suprarenal level is also possible. Thus, it facilitates the treatment AAA with short proximal nect or extending to suprarenal level.

Endovascular AAA repair can be applied under local, regional or general anesthesia. It is a technique which does not require major abdominal surgery. With this aspect, it is preferable in high-risk (serious cardiopulmonary disease or advanced age, accompanied morbid obesity and previous abdominal surgery) cases. However, after its feasibility is understood, it was started to be used in many patients with moderate and low risk patients with anatomical suitability. Its area of use gradually increases. 16 However, there are problematic conditions associated with this treatment modality in- 
cluding anatomical nonconformity, endoleak, graft occlusion, aortic balloon dilatation.

\section{The advantages of Endovascular}

\section{Treatment Moda-lity in AAA}

- Short period of procedure

- No cross-clamp use

- Less organ injury

- Less loss of blood, hence less blood transfusion

- Oral feeding within a short span of time

- Short duration of hospitalization

Due to great advancements in technology within the last 10 years, the tendency to EVAR as treatment modality in AAA cases has increased. In the upcoming years with more advanced devices, approximately $90 \%$ of AAA is thought to be treated with this method. ${ }^{(9)}$

In Izmir Ataturk Training and Research Hospital Cardiovascular Surgery Clinic, EVAR administration in AAA was started in 2003, and successfully applied to 68 patients with infrarenal AAA until the end of 2008. In our clinic, one of the pioneers of EVAR in the world and Turkey, open surgery treatment of AAA gradually decreases and EVAR treatment is increasing. (Figure 1)

Though the long-term mortality and morbidity results of patients who underwent endovascular treatment modalities are unknown, we recommend endovascular treatment to be administered in patients with high risk for open surgery and in centers with proper hybrid operating room conditions.

In view of the tendency for less invasive methods for the treatment option in recent years, cardiovascular surgeons should review their positions on this. Assuming the $52 \%$ of the vascular interventions in 2012 will be performed via endovascular routes, the importance of this will be understood again. Cardiovascular surgery specialists are at a crossroads.

Also, new regulations should be made with rapid review of training programs of Cardiovascular surgery. Our centers should understand the importance of hybrid operation room, and make efforts to establish them.

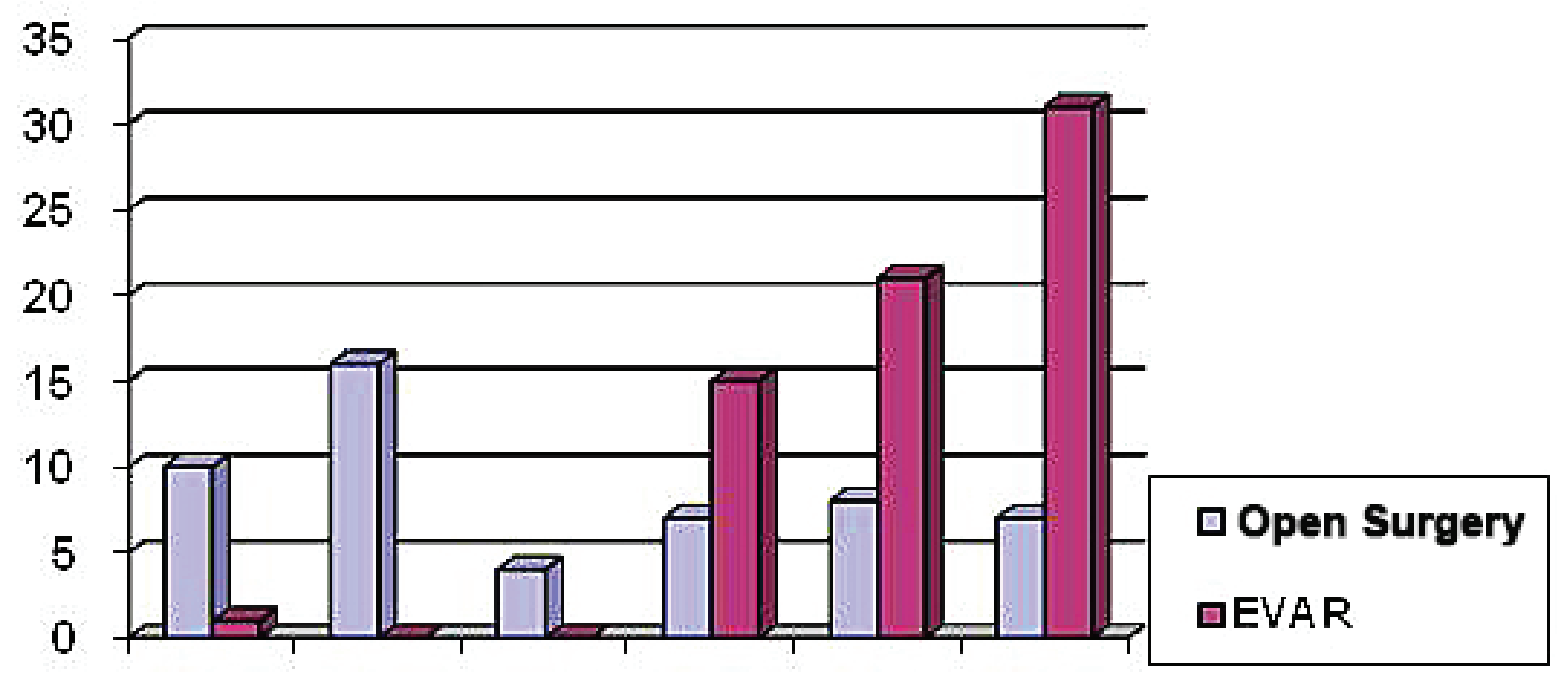

$\begin{array}{llllll}2003 & 2004 & 2005 & 2006 & 2007 & 2008\end{array}$ 


\section{References}

1. Ashton HA, Buxton MJ, Day NE, Kim LG, Marteau TM, Scott RA, Thompson SG, Walker NM; Multicentre Aneurysm Screening Study Group. The Multicentre Aneurysm Screening Study (MASS) into the effect of abdominal aortic aneurysm screening on mortality in men: a randomised controlled trial. Lancet. 2002 Nov 16;360(9345):1531-9.

2. Türk Kalp Damar Cerrahisi Derneği Aort Cerrahisinde Tanı ve Tedavi Kilavuzu-2008 :36-56;86-96.

3. Lederle FA, Wilson SE, Johnson GR, Reinke DB, Littooy FN, Acher CW, Ballard DJ, Messina LM, Gordon IL, Chute EP, Krupski WC, Busuttil SJ, Barone GW, Sparks S, Graham LM, Rapp JH, Makaroun MS, Moneta GL, Cambria RA, Makhoul RG, Eton D, Ansel HJ, Freischlag JA, Bandyk D; Aneurysm Detection and Management Veterans Affairs Cooperative Study Group. Immediate repair compared with surveillance of small abdominal aortic aneurysms. N Engl J Med. 2002 May 9;346(19):1437-44.

4. Kalp ve Damar Cerrahisi. Enver Duran. Cilt I;725-741

5. Bede SD, Ballard DJ, James EM, ve ark. Positive predictive value of clinical suspicion of abdominal aortic aneurysm: Implications for efficient use of abdominal Ultrasonography. Arch Intern Med. 1990;150;549

6. Sterpetti AV, Cavallaro A, Cavallari N, Allegrucci P, Tamburelli A, Agosta F, Bartoli S. Factors influencing the rupture of abdominal aortic aneurysms. Surg Gynecol Obstet. 1991 Sep;173(3):175-8.

7. Blankensteijn JD, Lindenburg FP, Van der Graaf Y, Eikelboom BC. Influence of study design on reported mortality and morbidity rates after abdominal aortic aneurysm repair Br J Surg. 1998 Dec;85(12):1624-30.

8. Johnston KW. Multicenter prospective study of nonruptured abdominal aortic aneurysm. Part II. Variables predicting morbidity and mortality J Vasc Surg. 1989 Mar;9(3):437-47

9. Muhammad S. Sajid, Mittal Desai, Zishan Haider, Daryll M. Baker and George Hamilton, Department of Vascular Surgery, Royal Free Hospital,
Hampstead, London, UK Endovascular Aortic Aneurysm Repair (EVAR) Has Significantly Lower Perioperative Mortality in Comparison to Open Repair: A Systematic Review Asian Journal of Surgery Vol 31:2008

10. Bown MJ, Sutton AJ, Bell PR, Sayers RD. A meta-analysis of 50 years of ruptured abdominal aortic aneurysm repair Br J Surg. 2002 Jun;89(6):714-30. Review.

11. Greenhalgh RM, Brown LC, Kwong GP, Powell JT, Thompson SG; EVAR trial participants. Comparison of endovascular aneurysm repair with open repair in patients with abdominal aortic aneurysm (EVAR trial 1), 30-day operative mortality results: randomised controlled trial Lancet. 2004 Sep 4-10;364(9437):843-8

12. Prinssen M, Verhoeven EL, Buth J, Cuypers PW, van Sambeek MR, Balm R, Buskens E, Grobbee DE, Blankensteijn JD; Dutch Randomized Endovascular Aneurysm Management (DREAM)Trial Group. A randomized trial comparing conventional and endovascular repair of abdominal aortic aneurysms N Engl J Med. 2004 Oct 14;351(16):1607-18

13. EVAR trial participants. Endovascular aneurysm repair versus open repair in patients with abdominal aortic aneurysm (EVAR trial 1): randomised controlled trial. Lancet. 2005 Jun 25-Jul 1;365(9478):2179-86

14. Blankensteijn JD, de Jong SE, Prinssen M, van der Ham AC, Buth J, van Sterkenburg SM, Verhagen HJ, Buskens E, Grobbee DE; Dutch Randomized Endovascular Aneurysm Management (DREAM) Trial Group. Two-year outcomes after conventional or endovascular repair of abdominal aortic aneurysms N Engl J Med. 2005 Jun 9;352(23):2398-405

15. Harris PL, Buth J. An update on the important findings from the EUROSTAR EVAR registry Vascular. 2004 Jan;12(1):33-8

16. Anderson PL, Arons RR, Moskowitz AJ, Gelijns A, Magnell C, Faries PL, Clair D, Nowygrod R, Kent KC. A statewide experience with endovascular abdominal aortic aneurysm repair: rapid diffusion with excellent early results J Vasc Surg. 2004 Jan;39 (1):10-9

Received: 23/11/2014

Accepted: 04/03/2015

Published: $15 / 10 / 2015$

Disclosure and conflicts of interest:

Conflicts of interest were not reported.

\section{Corresponding author:}

Prof. Dr. Ali Gürbüz

Mail: ali.gurbuz@ikc.edu.tr 